\title{
Spotlight on the Corneal Back Surface Astigmatism: A Review
}

\author{
Sudi Patel (1D) \\ Larysa Tutchenko ${ }^{2}$ \\ I"Svjetlost" Speciality Eye Hospital, \\ School of Medicine, University of Rijeka, \\ Zagreb, Croatia; ${ }^{2}$ Kyiv City Clinical \\ Ophthalmological Hospital "Eye \\ Microsurgical Center”, Kyiv, Ukraine
}

\begin{abstract}
Recent evidence indicates that the corneal back surface astigmatism (CBSA) contributes to the refractive state of the eye in cataract surgery, especially with the implantation of toric intraocular lenses. But this has been met with some scepticism. A review of key studies performed over the past three decades shows that the mean CBSA power ranges from $0.18( \pm 0.16) \mathrm{D}$ to $1.04( \pm 0.20) \mathrm{D}$. The clinical assessment of CBSA is problematic. There is poor agreement between the current automated systems for assessment of CBSA and it is assumed that these systems directly measure the CBSA. But CBSA cannot be measured directly in vivo. A historical review of methods used to quantify the curvature of the posterior corneal surface reveals that CBSA estimated by current systems is based on values for corneal front surface astigmatism, corneal refractive index, central corneal thickness, corneal thickness at peripheral locations and the exact distance between the corneal apex and each one of these peripheral locations. Doubts and errors in these values, coupled with the precise details of the algorithm incorporated to estimate CBSA, are the likely sources of the lack of agreement between current systems. These systematic errors cloud the assessment of CBSA. Mean CBSA may be low, but it varies from case to case. There is a clear need for a realistic, practical procedure for clinicians to independently calibrate systems for estimating CBSA. This would help to reduce uncertainty and the discrepancies between instruments designed to measure the same parameter.
\end{abstract}

Keywords: cornea, back surface, astigmatism, radius, thickness, refractive index

\section{Introduction}

The classical texts identified the corneal back surface as being a relatively inert intra-ocular optical boundary that had a negligible impact on the overall optical performance of the eye. ${ }^{1,2}$ Nevertheless, since 2000 there has been a resurgence of interest in the curvature, and in particular the astigmatism, of the corneal back surface. A quick check on "PubMed" leads to more than 200 hits after typing in "corneal posterior surface power." Changes in corneal back surface astigmatism are expected after most forms of keratoplasty, ${ }^{3-5}$ in cases of keratoconus, ${ }^{3,6-8}$ Fuchs' endothelial corneal dystrophy, ${ }^{8,9}$ and during refractive therapies including orthokeratology. ${ }^{10}$ In addition, corneal back surface astigmatism is claimed to impact on the performance of the eye in relation to refractive surgery ${ }^{11,12}$ and planning for cataract surgery especially in astigmatic eyes. ${ }^{13-25}$ Some investigators reported that corneal back surface astigmatism remains stable after refractive surgery, and this would have a marginal impact on later routine phacoemulsification. $^{26-32}$ This is certainly not the case in patients that underwent more invasive procedures, such as radial keratotomy, where profound changes in
Correspondence: Sudi Patel

Heinzelova 39, Zagreb, 10000, Croatia

Email drsudipatelI@gmail.com 
corneal back surface astigmatism can occur. ${ }^{33-35}$ Thus, it is reasonable to expect corneal back surface astigmatism to impact on refraction, and IOL power selection when such extraordinary cases request cataract surgery.

\section{Current Approaches for the Assessment of Back Corneal Astigmatism}

Total corneal astigmatism is modified by routine phacoemulsification and this alteration appears to be driven by the change in corneal back surface astigmatism on an individual case-by-case basis. ${ }^{36}$ But, to what extent does corneal back surface astigmatism vary within a typical sample drawn from a normal population? Table 1 lists the mean corneal back surface astigmatic power values reported in some of the key publications on this topic. The earliest publication reported a mean $( \pm$ s.d. $)$ corneal back surface astigmatic power value of $0.41( \pm 0.03) \mathrm{D} .^{37}$ The lowest, highest and typical mean values are 0.18 $( \pm 0.03) \mathrm{D},{ }^{38} 1.04( \pm 0.20) \mathrm{D},{ }^{39}$ and $0.26( \pm 0.15) \mathrm{D},{ }^{40}$ respectively. Most reported mean values were small, verging on the insignificant, but the range of values can be
$>0.75 \mathrm{D} .{ }^{22,41-43}$ The difference between the lowest and highest means is about 6.5 times greater when compared with the typical average \pm s.d value. Corneal back surface astigmatism cannot be measured directly. It is an estimate based on other measurements and assumptions. The lack of cohesion between these studies could be due to genuine differences between population samples or systematic differences in the way values for the corneal back surface astigmatism are derived.

The current crop of automated systems designed to provide values of corneal back surface astigmatism estimate the radius of curvature at multiple locations over the corneal back surface. Full descriptions of the more widely available systems can be found in a range of review articles and numerous websites. ${ }^{4-48}$ These radii are converted into power values, using the standard lens surface formula, assuming the refractive indices of the cornea and aqueous humour are 1.376 and 1.336 , respectively. When the orthogonal radii of the corneal back surface are $5.8 \mathrm{~mm}$ and $6.8 \mathrm{~mm}$ the corresponding respective powers are $-6.90 \mathrm{D}$ and $-5.88 \mathrm{D}$. Ray tracing through classical model eyes shows the impact on the refractive error is about

Table I Key Previous Estimates of Corneal Back Surface Astigmatism

\begin{tabular}{|c|c|c|c|}
\hline Authors & Year & Instrument/Method & Values (D) \\
\hline Dunne et $\mathrm{al}^{37}$ & 1992 & Purkinje Images & $\begin{array}{l}0.23( \pm 0.02, n=40, F) . \\
0.37( \pm 0.03, n=40, M)\end{array}$ \\
\hline Oshika et $\mathrm{al}^{38}$ & 1998 & Scanning Slit Video & $0.18( \pm 0.16, n=50)$ \\
\hline Liu et $\mathrm{al}^{39}$ & 1999 & Orbscan & $\begin{array}{l}0.37( \pm 0.18, n=94) \text { over } 3.0 \mathrm{~mm} \\
0.52( \pm 0.25, \mathrm{n}=94) \text { over } 5.0 \mathrm{~mm} \\
1.04( \pm 0.20, \mathrm{n}=94) \text { over } 7.0 \mathrm{~mm}\end{array}$ \\
\hline Dubbleman et $a^{63}$ & 2006 & Scheimpflug imaging & $0.31 \quad(n=114)$ \\
\hline Kamiya et $\mathrm{al}^{64}$ & 2015 & Pentacam HR & $0.44( \pm 0.12, n=53)$ \\
\hline Klijn et $\mathrm{al}^{22}$ & 2016 & Pentacam HR & $0.3 \mathrm{I}( \pm 0.17,0.01$ to $0.82, \mathrm{n}=77)$ \\
\hline Rydström et al ${ }^{40}$ & 2016 & Pentacam HR & $0.26( \pm 0.15, n=402)$ \\
\hline Choi et $\mathrm{al}^{65}$ & 2018 & Scheimpflug imaging & $0.39( \pm 0.18, n=33)$ \\
\hline Cui et al ${ }^{42}$ & 2019 & $\begin{array}{l}\text { Cassini } \\
\text { Pentacam HR }\end{array}$ & $\begin{array}{l}0.35(0.04-0.89, n=117) \\
0.29(0.00-0.80, n=117)\end{array}$ \\
\hline Li et $\mathrm{al}^{43}$ & 2019 & Sirius & $0.31( \pm 0.17,0.05-1.09, n=121)$ \\
\hline Wylęgała et $\mathrm{al}^{48}$ & 2020 & $\begin{array}{l}\text { Galilei G6 } \\
\text { Casia } 2 \\
\text { Revo NX }\end{array}$ & $\begin{array}{l}0.44(n=94) \text { over } 4.0 \mathrm{~mm} \\
0.52(n=94) \text { over } 3.2 \mathrm{~mm} \\
0.05(n=94) \text { over } 3.0 \mathrm{~mm}\end{array}$ \\
\hline
\end{tabular}

Notes: All mean values for astigmatism have been converted into plus cylinder format where necessary; Values in parentheses are \pm sd and ranges according to the corresponding publication (reference number is in superscript); Details of instruments, or methods, used by each group of investigators are noted as cited in the relevant publication. Abbreviations: D, units of astigmatic power (dioptres); F, females; M, males. 
$1.00 \mathrm{D}$ when the radius at this surface changes by $1 \mathrm{~mm} .^{2}$ There is a near 1:1 relationship between a change in corneal back surface astigmatism and change in overall refraction. The algorithm built in each device utilises these data to produce dioptral maps of the surfaces, identifies the orthogonal axes where the averaged dioptral values are highest and lowest in a small series of concentric zones covering the central cornea. The estimation of corneal back surface astigmatism is wholly reliant upon the limitations of the exact method employed to determine the radii over the central region of the corneal back surface.

It is reasonable to assume that there should be close agreement between different instruments designed to measure the same parameter. However, this is not the case regarding the corneal back surface astigmatism. There is a distinct lack of affinity between the corneal back surface astigmatism values obtained by one instrument when compared with another. ${ }^{16,42,48-51}$ For example, Nasser et $\mathrm{al}^{50}$ reported the limit of agreement between the Sirius and Pentacam devices for the estimation of corneal back surface astigmatism ranged from $-0.56 \mathrm{D}$ to $+0.31 \mathrm{D}$. Wylęgała et $\mathrm{a}^{48}$ compared the performance of Casia, Galilei G6 and Revo NX for the estimation of corneal back surface astigmatism in a series of 94 eyes. The mean values for the corneal back surface astigmatism according to these systems were $0.52 \mathrm{D}, 0.44 \mathrm{D}$ and $0.05 \mathrm{D}$, respectively. Savini et $\mathrm{al}^{51}$ compared the Sirius and Pentacam devices for the estimation of total corneal astigmatism and found the differences between the two systems amounted to $\geq 0.50 \mathrm{D}$ in over $20 \%$ of cases and the axes differed by $>10^{\circ}$ in over $40 \%$ of cases.

The diversity and range of these values lead to the conclusion that results from different instruments are not readily interchangeable. This impacts on our confidence in these estimates and questions the value and clinical relevance of corneal back surface astigmatism. But why are the current advanced technologies yielding such differences? To seek possible answers and gain a better understanding of the relative importance of corneal back surface astigmatism, it is necessary to consider how corneal back surface astigmatism has been estimated in the past, the rationale underpinning some of these procedures and the repeatability and validity of these various techniques.

\section{Estimating Corneal Back Surface Radii, Hence the Astigmatism}

During the early stages of 20th century, Tscherning $^{1}$ declared the radius of the corneal back surface was $6.22 \mathrm{~mm}$ while
Gullstrand $^{2}$ declared this radius was $6.80 \mathrm{~mm}$. A review of the pertinent literature shows that there was a paucity of interest in the radius and shape of the corneal back surface for about six decades. However, there are two publications where the quoted values are quite disparate. In 1973, Lowe and Clarke ${ }^{52}$ reported that the mean radius of this surface along the vertical meridian was typically $6.46 \mathrm{~mm}$, and seventeen years later Camellin ${ }^{53}$ estimated the mean radius was $5.84 \mathrm{~mm}$. This difference of $+0.62 \mathrm{~mm}$ changes the overall power of the eye by approximately $-0.75 \mathrm{D} .{ }^{54}$ This translates to a difference in astigmatism if the difference was orthogonal. Under normal circumstances it is hardly likely for the radius of curvature along one meridian at the corneal back to change by more than $0.50 \mathrm{~mm}$. Thus, little attention was paid to investigating the astigmatism and overall shape of the corneal back surface.

Tscherning ${ }^{1}$ measured the corneal back surface curvature by injecting the anterior chamber of cadaver eyes with liquid gelatin until it took up the shape of the corneal surface. The cornea was removed, after the gelatin had hardened, to reveal a convex cast of the corneal back surface. The radius of the cast mirrors the curvature of the corneal back surface. Moving on from this totally invasive method, he developed a non-invasive procedure for calculating corneal back surface astigmatism using an ophthalmophakometer (sic). The result obtained using this procedure is dependent upon five variables. Therefore, the validity of the final calculation of corneal back surface astigmatism is totally reliant upon the error in each one of the five variables.

Lowe and Clark ${ }^{52}$ captured slit-lamp images of the corneal profile and matched the shapes of the corneal surfaces with contours of known curvature. The physical limitations of the procedure meant that only an estimate for the corneal back surface radius along the vertical meridian could be made in each case. During that time, the resolution of profile photography for estimating the dimensions of the cornea was heavily criticised for being unreliable. ${ }^{55}$

Royston et a ${ }^{56,57}$ modified Tscherning's non-invasive procedure by capturing the 1st and 2nd Purkinje images of fixed targets positioned along 3 meridians, measuring the corneal front surface radii along the same 3 meridians and the central corneal thickness. The sizes of the Purkinje images together with the other measurements were used to calculate the corneal back surface radii along these meridians using a simple formula. In a series of 15 eyes, the RMS difference between the profile photography and Purkinje image methods for corneal back surface radius was $0.097 \mathrm{~mm}$ (range 0 to $0.20 \mathrm{~mm}$ ). This is equivalent to a difference in corneal back surface 
power of about $0.10 \mathrm{D} .^{57}$ The test-retest reliability of the Purkinje image technique, based on estimates of corneal back surface astigmatism obtained from 5 eyes, equates to less than $0.03 \mathrm{D}$ for power and $3^{\circ}$ for the axis. A subsequent paper by the same authors reported mean corneal back surface astigmatism values equivalent to $0.23 \mathrm{D}( \pm 0.02 \mathrm{D}, \mathrm{n}=40)$ in females and $0.37 \mathrm{D}( \pm 0.03 \mathrm{D}, \mathrm{n}=40)$ in males. ${ }^{37}$ The corresponding axis values were $88.6^{\circ}( \pm 4.8)$ and $91.7^{\circ}( \pm 4.5)$. Lam and Douthwaite ${ }^{58}$ used a similar procedure based on Purkinje images and reported that the typical difference between vertical and horizontal corneal back surface radii values was about $0.25 \mathrm{~mm}$. This equates to a corneal back surface astigmatism of about $0.30 \mathrm{D}$. To facilitate these procedures, the 1st and 2nd Purkinje images must remain separate and free of any overlap. This limitation means that corneal back surface assessments are made at distances about $3 \mathrm{~mm}$, or more, away from the apex of the cornea. Hence, the estimate of corneal back surface astigmatism is for a region of the central cornea no less than $6 \mathrm{~mm}$ in diameter. It has been shown that the back surface of the cornea flattens gradually from the apex. ${ }^{54,59}$ The radius at the apex of the back surface of the cornea is likely to be smaller compared with the figures obtained by these other methods. The actual astigmatism at the apex of the back surface of the cornea could exceed 0.30D in some cases.

Camellin $^{53}$ devised a geometric method for calculating the radius of the corneal back surface from measurements of front corneal surface radius and topographic corneal thickness. A further development of this technique was used to estimate not only the radius of the corneal back surface but also its' asphericity. ${ }^{54,59}$

\section{Fundamental Basis for the Estimation of Corneal Back Surface Radius and Astigmatism}

The precise details of the algorithms incorporated into any of the current generation of clinical instruments designed to determine corneal back surface astigmatism are, to some extent, trade secrets. However, Figure 1 shows how corneal back surface radii and astigmatism can be derived. Figure 1 is a diagrammatic representation of a corneal section where the front and back surfaces are centred about a common geometric axis. It can be shown that the radius of the back surface $\left(R_{2}\right)$ can be estimated using the following:

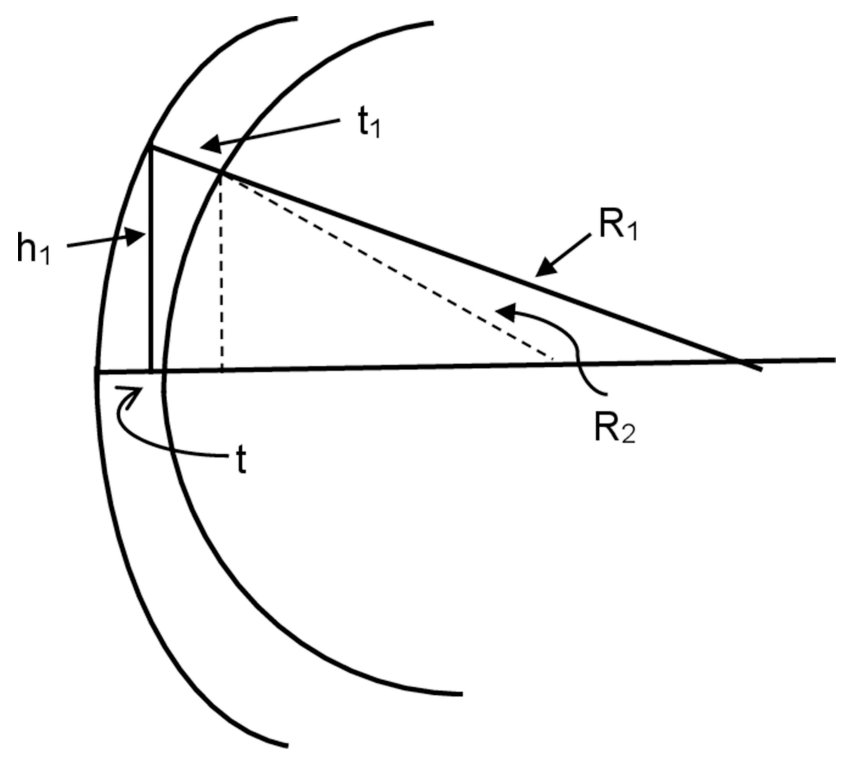

Figure I Diagram of a corneal section for the calculation of back surface radius. $h_{1}=$ distance from the apex of the cornea and a peripheral location on corneal surface, $t_{1}=$ thickness of the cornea at this peripheral location on corneal surface, $t=$ thickness at the apex of the cornea, $R_{1}=$ corneal front surface radius, $R_{2}=$ corneal back surface radius.

$$
\mathrm{R}_{2}=\frac{\mathrm{A}^{2}+(\mathrm{B}+\sqrt{\mathrm{C}}-\mathrm{t})^{2}}{2(\mathrm{~B}+\sqrt{ } \mathrm{C}-\mathrm{t})]}
$$

Where, $\mathrm{h}_{1}=$ distance from the apex of the cornea and a peripheral location on corneal surface, $t_{1}=$ thickness of the cornea at this peripheral location on corneal surface (ie, the length of the perpendicular stretching from this peripheral location on the corneal front surface to the corneal back surface), $t=$ thickness at the apex of the cornea, $R_{1}=$ corneal front surface radius, $A=h_{1}-\left(h_{1} \cdot t_{1} / R_{1}\right), B=R_{1}-\sqrt{ }\left(R_{1}^{2}-h_{1}{ }^{2}\right)$ and $C=t_{1}{ }^{2}+$ $\left(\mathrm{h}_{1} \cdot \mathrm{t}_{1} / \mathrm{R}_{1}\right)^{2}$.

The actual methods built-in the automated instruments for deriving the corneal back surface astigmatism are likely variations of the schema shown in Figure 1. The estimate of corneal back surface radius, hence the astigmatism, is dependent upon four measured variables, $t, t_{1}$, $h_{1}$ and $R_{1}$. The estimates of $t_{1}$ and $t$ also depend on the refractive index of the cornea. ${ }^{60}$

The numerical effect of errors in the measurement of, or changes in, the four variables in the estimation of $R_{2}$ can be quantified as follows: ${ }^{61}$

$$
\delta \mathrm{R}_{2}=\frac{\partial \mathrm{R}_{2}}{\partial \mathrm{t}} \cdot \delta \mathrm{t}+\frac{\partial \mathrm{R}_{2}}{\partial t_{1}} \cdot \delta t_{1}+\frac{\partial \mathrm{R}_{2}}{\partial h_{1}} \cdot \delta h_{1}+\frac{\partial \mathrm{R}_{2}}{\partial R_{1}} \cdot \delta R_{1} \quad \text { Eq. } 2
$$

The partial differential equations demonstrating the theoretical effects on the estimation of $R_{2}$ are shown in Table 2 . 
Table 2 Partial Differential Equations for the Relative Error, $\delta \mathrm{R}_{2}$, for in the Calculation of Corneal Back Surface Radius

\begin{tabular}{|l|l|}
\hline$\frac{\partial R_{2}}{\partial t}$ & {$[2(\mathrm{t}-\mathrm{B}-\sqrt{ } \mathrm{C}) \mathrm{V}-2 \mathrm{U}] / \mathrm{V}^{2}$} \\
\hline$\frac{\partial R_{2}}{\partial t_{1}}$ & {$\left[4\left(\mathrm{~K}_{1} \mathrm{t}_{1}\right)+2 \mathrm{t}_{1}-2 \mathrm{~h}_{1} \mathrm{~K}_{1}+\left\{2 \mathrm{~K}_{2}\left(\mathrm{t}_{1}+\mathrm{K}_{1} \mathrm{t}_{1}\right) / \sqrt{ }\left[\mathrm{t}_{1}{ }^{2}+\left(\mathrm{K}_{1} \mathrm{t}_{1}\right)^{2}\right]\right\}\right] / V-U\left\{2 \mathrm{t}_{1}\left(\mathrm{I}+\mathrm{K}_{1}\right) / \sqrt{ }\left[\mathrm{t}_{1}{ }^{2}+\left(\mathrm{K}_{1} \mathrm{t}_{1}\right)^{2}\right]\right\} / \mathrm{V}^{2}$} \\
\hline$\frac{\partial R_{2}}{\partial h_{1}}$ & $\mathrm{~h}_{1}\left(2+2 \mathrm{~K}_{5}{ }^{2}+4 \mathrm{~K}_{5}\right)+\left[2 \mathrm{~K}_{8}\left(\mathrm{~K}_{6}+\mathrm{K}_{7}\right)\right] / \mathrm{V}-\mathrm{U}\left(\mathrm{K}_{6}+2 \mathrm{~K}_{7}\right) / \mathrm{V}^{2}$ \\
\hline$\frac{\partial R_{2}}{\partial R_{1}}$ & $2\left\{\mathrm{~V}\left[\mathrm{~K}_{11}-\mathrm{K}_{12}+\left([\mathrm{B}-\mathrm{t}+\sqrt{ } \mathrm{C}] \times\left[1-\mathrm{K}_{9}-\mathrm{K}_{10}\right]\right)\right]-\mathrm{U}\left[\mathrm{I}-\mathrm{K}_{9}-\left(\mathrm{h}_{1}{ }^{2} \mathrm{t}_{1}{ }^{2} / \mathrm{R}_{1}{ }^{3} \sqrt{ } \mathrm{C}\right)\right]\right\} / V^{2}$ \\
\hline
\end{tabular}

Notes: Where, with reference to Figure $\mathrm{I}, \mathrm{h}_{1}=$ distance from the apex of the cornea and a peripheral location on corneal surface, $t_{1}=$ the length of the perpendicular stretching from this peripheral location on the corneal front surface to the peripheral corneal surface (ie, the thickness of the cornea at this peripheral location); $t=$ thickness at the apex of the cornea; $R_{1}=$ corneal front surface radius, and $A=h_{1}-\left(h_{1} t_{1} / R_{1}\right) ; B=R_{1}-\sqrt{ }\left(R_{1}{ }^{2}-h_{1}{ }^{2}\right) ; C=t_{1}{ }^{2}+\left(h_{1} t_{1} / R_{1}\right)^{2} ; U=A^{2}+(B+\sqrt{ } C-t)^{2} ; V=2(B+\sqrt{ } C-$ $t) ; K_{1}=h_{1} / R_{1} ; K_{2}=B-t ; K_{3}=K_{1}+1 ; K_{4}=h_{1} t_{1} ; K_{5}=t_{1} / R_{1} ; K_{6}=h_{1} / \sqrt{ }\left(R_{1}{ }^{2}-h_{1}{ }^{2}\right) ; K_{7}=h_{1} K_{5}{ }^{2} / \sqrt{ }\left(t_{1}{ }^{2}+\left[h_{1} K_{5}\right]^{2}\right) ; K_{8}=B+\sqrt{ }\left(t_{1}{ }^{2}+\left[h_{1} K_{5}\right]^{2} ; K_{9}=R_{1} / \sqrt{ }\left(R_{1}{ }^{2}-h_{1}{ }^{2}\right) ; K_{10}=h_{1}{ }^{2} t_{1}{ }^{2} / R_{1}{ }^{3} \sqrt{ } C\right] ;$ $\mathrm{K}_{11}=\mathrm{h}_{1}{ }^{2} \mathrm{t}_{1} / \mathrm{R}_{1}{ }^{2} ; \mathrm{K}_{12}=\mathrm{h}_{1}{ }^{2} \mathrm{t}_{1}{ }^{2} / \mathrm{R}_{1}{ }^{3}$.

For typical values of $R_{1}(7.7 \mathrm{~mm}), h_{1}(2.0 \mathrm{~mm}), \mathrm{t}_{1}$ $(0.52 \mathrm{~mm})$, and $\mathrm{t}(0.50 \mathrm{~mm})$ reduces Equation 2 to:

$$
\delta R_{2}=19.00 \delta t-19.79 \delta t_{1}-2.26 \delta h_{1}+0.75 \delta R_{1} \text { Eq. } 3
$$

When errors in the measurement of $\delta \mathrm{R}_{1}, \delta \mathrm{h}_{1}, \delta \mathrm{t}_{1}$ and $\delta \mathrm{t}=$ $+0.01 \mathrm{~mm}$, then $\delta \mathrm{R}_{2}=-0.02 \mathrm{~mm}$. This is an indication of the accuracy in the determination, that is the difference between the true and estimated value, of $R_{2}$. The value of $\delta R_{2}$ is negative and indicative of an overestimate of corneal back radius.

In normal eyes, the average change in the astigmatic power of the ocular surface during short intervals of blink suppression is about $0.48 \mathrm{D}$ over the central pupillary region of the cornea. ${ }^{62}$ Such a change in ocular surface power would occur when the orthogonal difference in ocular surface radii is about $0.1 \mathrm{~mm}$. Therefore, it is reasonable to adopt $+0.1 \mathrm{~mm}$ as a more realistic clinical estimate for $\delta \mathrm{R}_{1}$. For $\delta \mathrm{R}_{1}=+0.1 \mathrm{~mm}$, keeping $\delta \mathrm{R}_{1}, \delta \mathrm{h}_{1}, \delta \mathrm{t}_{1}$ and $\delta \mathrm{t}=+0.01 \mathrm{~mm}$, then $\delta \mathrm{R}_{2}=+0.04 \mathrm{~mm}$. The value of $\delta \mathrm{R}_{2}$ is now positive and indicative of an underestimate of corneal back radius. This value for $\delta R_{2}$ is equivalent to an error in corneal back surface power of about $-0.04 \mathrm{D}$. As this is the result of a change in ocular surface astigmatism, then $0.04 \mathrm{D}$ is a reasonable estimate for the absolute limit of accuracy in the practical determination of corneal back surface astigmatic power.

Nasser et $\mathrm{al}^{50}$ found the limits of agreement between the Sirius and Pentacam for the estimation of corneal front surface astigmatism ranged from $-0.1 \mathrm{~mm}$ to $0.12 \mathrm{~mm}$. The extent of this range, $0.22 \mathrm{~mm}$, equates to a range in the limit of agreement for corneal front surface astigmatism of over $1.25 \mathrm{D}$. This being the range where most of the differences in the estimation of corneal front surface astigmatism lie. Adopting these as values, $-0.1 \mathrm{~mm}$ and $0.12 \mathrm{~mm}$, for $\delta \mathrm{R}_{1}$ in Equation 3 results in hypothetical values for $\delta \mathrm{R}_{2}$ ranging from $-0.10 \mathrm{~mm}$ to $+0.06 \mathrm{~mm}$ when $\delta \mathrm{h}_{1}, \delta \mathrm{t}_{1}$ and $\delta \mathrm{t}=+0.01 \mathrm{~mm}$. The actual limits of agreement for the corneal back surface astigmatism (in $\mathrm{mm}$ ) reported by Nasser et $\mathrm{al}^{50}$ ranged from $-0.54 \mathrm{~mm}$ to $+0.33 \mathrm{~mm}$. This range, $0.87 \mathrm{~mm}$, is 5.4 times greater than the hypothetical range of $\delta R_{2}$ values of $-0.10 \mathrm{~mm}$ to $+0.06 \mathrm{~mm}$. In addition, inter-device differences in the estimation of mean corneal thickness can be up to $0.030 \mathrm{~mm} .^{48}$ Thus, other factors, other values for the uncertainties or differences in $h_{1}, t_{1}$ or $\mathrm{t}$ besides $+0.01 \mathrm{~mm}$ could account for the range $-0.54 \mathrm{~mm}$ to $+0.33 \mathrm{~mm}$. Equation 3 predicts uncertainties in $\delta \mathrm{t}_{1}$ and $\delta \mathrm{t}$ are not expected to have much impact on $\delta R_{2}$ when the uncertainties in these parameters are in the same direction, either positive or negative, as such directional uncertainties will cancel each other out. However, by how much does $\delta \mathrm{R}_{2}$ vary should $\delta \mathrm{t}_{1}=+0.01 \mathrm{~mm}$ along one meridian and $-0.01 \mathrm{~mm}$ along another? According to Equation 3, for $\delta \mathrm{R}_{1}=+0.1 \mathrm{~mm}, \delta \mathrm{h}_{1}$ and $\delta \mathrm{t}=+0.01 \mathrm{~mm}, \delta \mathrm{R}_{2}=-0.11 \mathrm{~mm}$ when $\delta \mathrm{t}_{1}=+0.01 \mathrm{~mm}$ and $+0.29 \mathrm{~mm}$ when $\delta \mathrm{t}_{1}=-0.01 \mathrm{~mm}$. This positive-to-negative shift in $\delta t_{1}$ alters $\delta R_{2}$ by $+0.40 \mathrm{~mm}$. This change in $\delta \mathrm{R}_{2}$ increases to $+0.59 \mathrm{~mm}$ when the $\delta \mathrm{t}_{1}$ values are adjusted to $-0.015 \mathrm{~mm}$ and $+0.015 \mathrm{~mm}$. Such uncertainty in $\delta R_{2}$ is equivalent to an uncertainty in corneal back surface astigmatism, and overall refraction, of just under $0.75 \mathrm{D}$. Clearly, there is a profound impact on $\delta R_{2}$ when the regional uncertainties in $\delta \mathrm{t}_{1}$ consist of positive and negative values. Inter-device differences for the estimation of corneal back surface astigmatism are amplified when the direction (positive or negative) of uncertainties in the pachymetric estimations is inconsistent. This partially, but not fully, accounts for the reported limits of agreement in the estimation of corneal back surface astigmatism ranging from $-0.54 \mathrm{~mm}$ to $+0.33 \mathrm{~mm}^{50}$

Turning to $\delta h_{1}$, by how much should this potential source of uncertainty fluctuate to account for these wide limits of 
agreement? According to Equation 3, when $\delta \mathrm{R}_{1}=+0.1 \mathrm{~mm}$ and $\delta \mathrm{t}_{1}$ and $\delta \mathrm{t}=+0.01 \mathrm{~mm}$, the value of $\delta \mathrm{R}_{2}$ shifts from $-0.54 \mathrm{~mm}$ to $+0.34 \mathrm{~mm}$ by changing $\delta \mathrm{h}_{1}$ from $+0.27 \mathrm{~mm}$ to $-0.12 \mathrm{~mm}$. The impact of this hypothetical shift in $\delta \mathrm{h}_{1}$ on the estimation of corneal back surface astigmatism is just below 1D. Therefore, it is possible for small systematic, meridionally sensitive, differences in the algorithms used by these devices to contribute towards the variations in corneal back surface astigmatism estimates between instruments. Random errors, occurring during the clinical comparison of devices designed to quantify corneal back surface astigmatism, would also contribute to the variance in the data. But such random errors would mask any real differences in the estimation of corneal back surface astigmatism and prevent statistically significant differences from being detected. When the differences between the acquired results are either clinically or statistically significant different, then the reasons are most likely due to systematic differences in the way different devices operate to quantify the same parameter.

\section{Conclusion}

The actual astigmatism at the back surface of the cornea cannot yet be measured directly. This astigmatism is an estimate based on several assumptions including the topographic changes in the thickness and front surface radii of the cornea. The hypothetical analysis stemming from Equation 1 is based on several assumptions, such as both corneal surfaces are centred on a common axis, the length of the distances separating the surfaces is perpendicular to the front surface, and it is two dimensional. The analysis does not readily cater for differences in the axes of astigmatism between the corneal surfaces. Furthermore, the dimensions of $R_{1}, t, t_{1}$ and $h_{1}$ must be known. None of these factors is measured directly except for $h_{1}$. $R_{1}$ is an indirect estimate based on the calibration procedures adopted by the manufacturer. Non-contact pachymeters measure the width of the corneal section at various locations and the final computation of $t$ and $t_{1}$ rests solely upon the algorithm employed by the manufacturer to interpret the dimensions of the corneal section. The computed $t$ and $t_{1}$ values are wavelength dependent and influenced by the refractive index value adopted by the manufacturer. It comes as no surprise that different instruments will provide different estimates of corneal back surface astigmatism when the machines estimate topographic variations in corneal thickness by different rules and algorithms. In addition, the automated systems designed to measure corneal back astigmatism locate the apex of the corneal front surface, while the subject fixates centrally as part of the operational procedure. It is assumed that the location of the 1st Purkinje image is coincident with the apex of the corneal front surface and the visual axis passes through the centre of the pupil. Thus, the true values of both angles kappa and alpha also carry the potential to impact on the estimation of corneal back surface astigmatism. The estimate of corneal back surface astigmatism is an educated guess. It would be a well-educated guess if there was closer, more clinically acceptable, agreement between the results of one instrument and another. It is incumbent on the industry to reach a compromise so that different technologies yield largely similar results. It would be useful if a universally acceptable and realistic model, a procedure, was made available allowing clinics to independently calibrate their system for estimating corneal back surface astigmatism. Such actions would help reduce uncertainty and the discrepancies between instruments designed to measure the same parameter.

\section{Disclosure}

The authors report no conflicts of interest in this work.

\section{References}

1. Tscherning MME. The optic system of the eye. In: Tscherning MME, Weiland C, editors. Physiological Optics- Dioptrics of the Eye, Functions of the Retina, Ocular Movements and Binocular Vision. Philadelphia: Keystone; 1904:27.

2. Gullstrand A, Southall JPC, editor. Helmholtz's Treatise on Physiological Optics. Volumes I and II Appendix 1911. 1st ed. New York: Dover; 1962:325-351

3. Savini G, Barboni P, Carbonelli M, Hoffer KJ. Repeatability of automatic measurements by a new Scheimpflug camera combined with Placido topography. J Cataract Refract Surg. 2011;37(10):1809-1816. doi:10.1016/j.jcrs.2011.04.033

4. Ham L, Dapena I, Moutsouris K, et al. Refractive change and stability after Descemet membrane endothelial keratoplasty. Effect of corneal dehydration-induced hyperopic shift on intraocular lens power calculation. J Cataract Refract Surg. 2011;37(8):1455-1464. doi:10.1016/j.jcrs.2011.02.033

5. Langenbucher A, Szentmáry N, Spira C, Seitz B, Eppig T. Corneal power after Descemet stripping automated endothelial keratoplasty (DSAEK) - Modeling and concept for calculation of intraocular lenses. Z Med Phys. 2016;26(2):120-126. doi:10.1016/j.zemedi.20 15.02 .003

6. Mostafa EM. Comparison between corneal elevation maps using different reference surfaces with Scheimpflug-Placido topographer. Int Ophthalmol. 2017;37(3):553-558. doi:10.1007/s10792-016-0291-7

7. de Luis Eguileor B, Arriola-Villalobos P, Pijoan Zubizarreta JI, et al. Multicentre study: reliability and repeatability of Scheimpflug system measurement in keratoconus. Br J Ophthalmol. 2021;105(1):22-26. doi:10.1136/bjophthalmol-2019-314954

8. Ramos IC, Belin MW, Valbon BF, et al. Keratoconus associated with Corneal Guttata. Int J Kerat Ect Cor Dis. 2012;1(3):173-178. 
9. Wacker K, McLaren JW, Patel SV. Directional posterior corneal profile changes in fuchs' endothelial corneal dystrophy. Invest Ophthalmol Vis Sci. 2015;56(10):5904-5911. doi:10.1167/iovs.15-17311

10. Queirós A, Villa-Collar C, Gutiérrez ÁR, et al. Anterior and posterior corneal elevation after orthokeratology and standard and customized LASIK surgery. Eye Contact Lens. 2011;37(6):354-358. doi:10.1097/ ICL.0b013e318232e32d

11. Cheng AC, Ho T, Lau S, Lam DS. Evaluation of the apparent change in posterior corneal power in eyes with LASIK using Orbscan II with magnification compensation. J Refract Surg. 2009;25(2):221-228.

12. Wang J, Lopes BT, Li H, et al. Unintended changes in ocular biometric parameters during a 6-month follow-up period after FS-LASIK and SMILE. Eye Vis (Lond). 2021;8(1):9. PMID: 33741072; PMCID: PMC7977186. doi:10.1186/s40662-021-00232-8

13. Cheng LS, Tsai CY, Tsai RJ, Liou SW, Ho JD. Estimation accuracy of surgically induced astigmatism on the cornea when neglecting the posterior corneal surface measurement. Acta Ophthalmol. 2011;89 (5):417-422. doi:10.1111/j.1755-3768.2009.01732.x

14. Koch DD, Ali SF, Weikert MP, Shirayama M, Jenkins R, Wang L. Contribution of posterior corneal astigmatism to total corneal astigmatism. J Cataract Refract Surg. 2012;38(12):2080-2087. doi:10.1016/j.jcrs.2012.08.036

15. Miyata K, Otani S, Honbou N, Minami K. Use of Scheimpflug corneal anterior-posterior imaging in ray-tracing intraocular lens power calculation. Acta Ophthalmol. 2013;91(7):546-549. doi:10.1111/aos.12139

16. Tejedor J, Guirao A. Agreement between refractive and corneal astigmatism in pseudophakic eyes. Cornea. 2013;32(6):783-790. doi:10.1097/ICO.0b013e31826dd44b

17. Eom Y, Kang SY, Kim HM, Song JS. The effect of posterior corneal flat meridian and astigmatism amount on the total corneal astigmatism estimated from anterior corneal measurements. Graefes Arch Clin Exp Ophthalmol. 2014;252(11):1769-1777. doi:10.1007/ s00417-014-2737-9

18. Nemeth G, Berta A, Szalai E, Hassan Z, Modis L Jr. Analysis of surgically induced astigmatism on the posterior surface of the cornea. J Refract Surg. 2014;30(9):604-608. doi:10.3928/1081597X-20140723-01

19. Savini G, Versaci F, Vestri G, Ducoli P, Næser K. Influence of posterior corneal astigmatism on total corneal astigmatism in eyes with moderate to high astigmatism. J Cataract Refract Surg. 2014;40 (10):1645-1653. doi:10.1016/j.jcrs.2014.01.046

20. Savini G, Næser K. An analysis of the factors influencing the residual refractive astigmatism after cataract surgery with toric intraocular lenses. Invest Ophthalmol Vis Sci. 2015;56(2):827-835. doi:10.1167/iovs.14-15903

21. Preussner PR, Hoffmann P, Wahl J. Impact of posterior corneal surface on toric intraocular lens (IOL) calculation. Curr Eye Res. 2015;40(8):809-814. doi:10.3109/02713683.2014.959708

22. Klijn S, van der Sommen CM, Sicam VA, Reus NJ. Value of posterior keratometry in the assessment of surgically induced astigmatic change in cataract surgery. Acta Ophthalmol. 2016;94(5):494-498.

23. Park DY, Lim DH, Hwang S, Hyun J, Chung TY. Comparison of astigmatism prediction error taken with the Pentacam measurements, Baylor nomogram, and Barrett formula for toric intraocular lens implantation. BMC Ophthalmol. 2017;17(1):156. PMID: 28836956; PMCID: PMC5571625. doi:10.1186/s12886-017-0550-z

24. Bandeira F, Morral M, Elies D, et al. Transitional conic toric intraocular lens for the management of corneal astigmatism in cataract surgery. Clin Ophthalmol. 2018;12:1071-1079. PMID: 29922036. doi:10.2147/OPTH.S148599

25. Gao Y, Ye Z, Chen W, Li J, Yan X, Li Z. Management of cataract in patients with irregular astigmatism with regular central component by phacoemulsification combined with toric intraocular lens implantation. J Ophthalmol. 2020:3520856. PMID: 32411427. doi: $10.1155 / 2020 / 3520856$
26. Seitz B, Torres F, Langenbucher A, Behrens A, Suárez E. Posterior corneal curvature changes after myopic laser in situ keratomileusis. Ophthalmology. 2001;108(4):666-672. doi:10.1016/S0161-6420(00) 00581-9

27. Seitz B, Langenbucher A, Torres F, Behrens A, Suárez E. Changes of posterior corneal astigmatism and tilt after myopic laser in situ keratomileusis. Cornea. 2002;21(5):441-446. doi:10.1097/ 00003226-200207000-00001

28. Du CX, Shen Y, Huang ZM, Xin SH. Characteristics and correlative factors of posterior corneal surface changes after laser in situ keratomileusis. Zhonghua Yan Ke Za Zhi. 2005;41(6):488-491.

29. Twa MD, Roberts C, Mahmoud AM, Chang JS Jr. Response of the posterior corneal surface to laser in situ keratomileusis for myopia. $J$ Cataract Refract Surg. 2005;31(1):61-71. doi:10.1016/j. jcrs.2004.09.032

30. Ciolino JB, Khachikian SS, Cortese MJ, Belin MW. Long-term stability of the posterior cornea after laser in situ keratomileusis. J Cataract Refract Surg. 2007;33(8):1366-1367. doi:10.1016/j.jcrs.2007.04.016

31. Nishimura R, Negishi K, Saiki M, et al. No forward shifting of posterior corneal surface in eyes undergoing LASIK. Ophthalmology. 2007;114(6):1104-1110. doi:10.1016/j. ophtha.2006.09.014

32. Khairat YM, Mohamed YH, Moftah IA, Fouad NN. Evaluation of corneal changes after myopic LASIK using the Pentacam ${ }^{\circledR}$. Clin Ophthalmol. 2013;7:1771-1776.

33. Camellin M, Savini G, Hoffer KJ, Carbonelli M, Barboni P. Scheimpflug camera measurement of anterior and posterior corneal curvature in eyes with previous radial keratotomy. J Refract Surg. 2012;28(4):275-279. doi:10.3928/1081597X-20120221-03

34. Meduri A, Urso M, Signorino GA, Rechichi M, Mazzotta C, Kaufman S. Cataract surgery on post radial keratotomy patients. Int J Ophthalmol. 2017;10(7):1168-1170.

35. Tsyrenzhapova EK, Rozanova OI, Seliverstova NN. Analysis of optical properties of posterior surface of cornea in patients after anterior radial keratotomy. Acta Biomed Sci. 2019;4(4):24-29. doi:10.29413/ABS.2019-4.4.3

36. Tutchenko L, Patel S, Voytsekhivskyy O, Skovron M, Horak O. The influence of routine uncomplicated phacoemulsification on the orthogonality of the cornea. Indian J Ophthalmol. 2021;69(5):1073-1079. doi:10.4103/ijo.IJO 116820

37. Dunne MC, Royston JM, Barnes DA. Normal variations of the posterior corneal surface. Acta Ophthalmol (Copenh). 1992;70 (2):255-261. doi:10.1111/j.1755-3768.1992.tb04133.x

38. Oshika T, Tomidokoro A, Tsuji H. Regular and irregular refractive powers of the front and back surfaces of the cornea. Exp Eye Res. 1998;67(4):443-447. doi:10.1006/exer.1998.0558

39. Liu Z, Huang AJ, Pflugfelder SC. Evaluation of corneal thickness and topography in normal eyes using the Orbscan corneal topography system. $\mathrm{Br} \quad J$ Ophthalmol. 1999;83(7):774-778. doi:10.1136/ bjo.83.7.774

40. Rydström E, Westin O, Koskela T, Behndig A. Posterior corneal astigmatism in refractive lens exchange surgery. Acta Ophthalmol. 2016;94(3):295-300. doi:10.1111/aos.12965

41. Miyake T, Shimizu K, Kamiya K. Distribution of posterior corneal astigmatism according to axis orientation of anterior corneal astigmatism. PLoS One. 2015;10(1):e0117194. PMID: 25625283; PMCID: PMC4307987. doi:10.1371/journal.pone.0117194

42. Cui XH, Yoo YS, An Y, Joo CK. Comparison of keratometric measurements between color light-emitting diode topography and Scheimpflug camera. BMC Ophthalmol. 2019;19(1):98. PMID: 31027491; PMCID: PMC6486681. doi:10.1186/s12886-019-1106-1

43. Li C, Zhang J, Yin X, Li J, Cao Y, Lu P. Distribution and related factors of corneal regularity and posterior corneal astigmatism in cataract patients. Clin Ophthalmol. 2019;13:1341-1352. doi:10.2147/OPTH.S212946 
44. Gosavi VV, Hardten DR. Developments in diagnostic tools for corneal ectasia. Expert Rev Ophthalmol. 2010;5(4):475-481. doi:10.1586/eop. 10.40

45. Ramamurthy S, Reddy JC, Jhanji V. Topography and tomography in the diagnosis of corneal ectasia. Expert Rev Ophthalmol. 2015;10 (3):215-228. doi:10.1586/17469899.2015.1044979

46. Oliveira CM, Ribeiro C, Franco S. Corneal imaging with slit-scanning and Scheimpflug imaging techniques. Clin Exp Optomol. 2011;94(1):33-42. doi:10.1111/j.1444-0938.2010.00509.x

47. Piñero DP. Technologies for anatomical and geometric characterization of the corneal structure and anterior segment: a review. Semin Ophthalmol. 2015;30(3):161-170. doi:10.3109/08820538.20 13.835844

48. Wylęgała A, Mazur R, Bolek B, Wylęgała E. Reproducibility, and repeatability of corneal topography measured by Revo NX, Galilei G6 and Casia 2 in normal eyes. PLoS One. 2020;15(4):e0230589. PMID: 32240192; PMCID: PMC7117679. doi:10.1371/journal. pone.0230589

49. Savini G, Carbonelli M, Sbreglia A, Barboni P, Deluigi G, Hoffer KJ. Comparison of anterior segment measurements by 3 Scheimpflug tomographers and 1 Placido corneal topographer. J Cataract Refract Surg. 2011;37(9):1679-1685. doi:10.1016/j.jcrs.2011.03.055

50. Nasser CK, Singer R, Barkana Y, Zadok D, Avni I, Goldich Y. Repeatability of the Sirius imaging system and agreement with the Pentacam HR. J Refract Surg. 2012;28(7):493-497. doi:10.3928/ 1081597X-20120619-01

51. Savini G, Næser K, Schiano-Lomoriello D, Ducoli P. Total corneal astigmatism measurements: agreement between 2 rotating Scheimpflug cameras. Cornea. 2017;36(4):463-469. doi:10.1097/ ICO.0000000000001117

52. Lowe RF, Clark BA. Posterior corneal curvature. Correlations in normal eyes and in eyes involved with primary angle-closure glaucoma. $\mathrm{Br} J$ Ophthalmol. 1973;57(7):464-470. doi:10.1136/ bjo.57.7.464

53. Camellin M. Proposed formula for the dioptric power evaluation of the posterior corneal surface. Refract Corneal Surg. 1990;6 (4):261-264. doi:10.3928/1081-597X-19900701-07

54. Patel S, Marshall J, Fitzke FW. Shape and radius of posterior corneal surface. Refract Corneal Surg. 1993;9(3):173-181. doi:10.3928/ 1081-597X-19930501-05
55. Smith TW. Corneal topography. Doc Ophthalmol. 1977;43 (2):249-276. doi:10.1007/BF01569199

56. Royston JM, Dunne MC, Barnes DA. Measurement of posterior corneal surface toricity. Optom Vis Sci. 1990;67(10):757-763. doi:10.1097/00006324-199010000-00002

57. Royston JM, Dunne MC, Barnes DA. Measurement of the posterior corneal radius using slit lamp and Purkinje image techniques. Ophthalmic Physiol Opt. 1990;10(4):385-388. doi:10.1111/j.14751313.1990.tb00886.x

58. Lam AK, Douthwaite WA. A pilot study on the measurement of central posterior corneal radius in Hong Kong Chinese using Purkinje image technique. Ophthalmic Physiol Opt. 1997;17 (1):68-74. doi:10.1111/j.1475-1313.1997.tb00526.x

59. Lam AK, Douthwaite WA. Measurement of posterior corneal asphericity on Hong Kong Chinese: a pilot study. Ophthalmic Physiol Opt. 1997;17(4):348-356. doi:10.1111/j.1475-1313.1997.tb00066.x

60. Patel S. Some theoretical factors governing the accuracy of corneal thickness measurement. Ophthalmic Physiol Opt. 1981;1(3):193-203. doi:10.1111/j.1475-1313.1981.tb00391.x

61. Thomas GB. Calculus and Analytic Geometry Parts I \& II. 1st ed. London: Addison-Wesley; 1972:824.

62. Mrukwa Kominek E, Sarnat-Kucharczyk M, Patel S. The impact of exposure on the magnitude of astigmatism formed within the precorneal tear film over the central optical zone of the cornea in ocular surface disease. Cont Lens Anterior Eye. 2020;43(3):261-267. doi:10.1016/j.clae.2020.01.002

63. Dubbelman M, Sicam VA, Van der Heijde GL. The shape of the anterior and posterior surface of the aging human cornea. Vision Res. 2006;46(6-7):993-1001. doi:10.1016/j.visres.2005.09.021

64. Kamiya K, Shimizu K, Yamagishi M, Igarashi A, Kobashi H. Anterior and posterior corneal astigmatism after refractive lenticule extraction for myopic astigmatism. J Ophthalmol PMID: 26097749; PMCID: PMC4443750. 2015;2015:915853. doi:10.1155/2015/ 915853

65. Choi Y, Eom Y, Song JS, Kim HM. Comparison of anterior, posterior, and total corneal astigmatism measured using a single Scheimpflug camera in healthy and keratoconus Eyes. Korean J Ophthalmol. 2018;32(3):163-171. doi:10.3341/kjo.2017.0075
Clinical Ophthalmology

\section{Publish your work in this journal}

Clinical Ophthalmology is an international, peer-reviewed journal covering all subspecialties within ophthalmology. Key topics include: Optometry; Visual science; Pharmacology and drug therapy in eye diseases; Basic Sciences; Primary and Secondary eye care; Patient Safety and Quality of Care Improvements. This journal is indexed on PubMed
Central and CAS, and is the official journal of The Society of Clinical Ophthalmology (SCO). The manuscript management system is completely online and includes a very quick and fair peer-review system, which is all easy to use. Visit http://www.dovepress.com/ testimonials.php to read real quotes from published authors.

\section{Dovepress}

